\title{
A MAINTENANCE STRATEGY MODEL FOR STATIC EQUIPMENT USING INSPECTION METHODOLOGIES AND RISK MANAGEMENT
}

\author{
J.K. Visser and J. Jordaan ${ }^{1}$ \\ Graduate School of Technology Management \\ University of Pretoria, South Africa \\ krige.visser@up.ac.za
}

\begin{abstract}
Mechanical equipment used on process plants can be categorised into two main types, namely static and rotating equipment. A brief survey at a number of chemical process plants indicated that a number of maintenance strategies exist and are used for rotating equipment. However, some of these strategies are not directly applicable to static equipment, although the risk-based inspection (RBI) methodology has been developed for pressure vessels. A generalised risk-based maintenance strategy for all types of static equipment does not currently exist. This paper describes the development of an optimised model of inspection methodologies, maintenance strategies, and risk management principles that are generically applicable for static equipment. It enables maintenance managers and engineers to select an applicable maintenance strategy and inspection methodology, based on the operational and business risks posed by the individual pieces of equipment.
\end{abstract}

\section{OPSOMMING}

Meganiese toerusting wat op prosesaanlegte gebruik word kan in twee kategorieë verdeel word, naamlik statiese en roterende toerusting. ' $n$ Bondige ondersoek by ' $n$ aantal chemiese prosesaanlegte het aangedui dat 'n aantal strategieë vir instandhouding van roterende toerusting gebruik word, terwyl die risikogebaseerde inspeksiemetodologie wel vir drukvate gebruik word. ' $n$ Algemene risikogebaseerde instandhoudingstrategie vir alle tipes statiese toerusting is egter nie tans beskikbaar nie. Hierdie artikel beskryf die ontwikkeling van 'n geoptimeerde model van inspeksiemetodologieë, instandhoudingstrategieë, en risikobestuursbeginsels wat algemeen gebruik kan word vir statiese toerusting. Dit stel die instandhouding-bestuurders en -ingenieurs in staat om ' $n$ instandhoudingstrategie en inspeksie-metodologie te kies, gebaseer op die operasionele en besigheidsrisiko's van die individuele toerusting.

\footnotetext{
${ }^{1}$ This author was enrolled for the MSc (Applied Sciences) degree at the Graduate School of Technology Management (GSTM), University of Pretoria.
} 


\section{INTRODUCTION}

\section{$1.1 \quad$ Background}

Maintenance management has five main functions: 1) maintenance planning, 2) maintenance organising, 3) maintenance staffing, 4) maintenance leading, and 5) maintenance controlling (Visser [1]). Over the past twenty years, maintenance has changed, perhaps more so than any other management discipline. These changes are due to the huge increase in the number and variety of physical assets (plant, equipment, and buildings) that must be maintained throughout the world, and to much more complex designs, new maintenance techniques, and changing views on maintenance organisation and responsibilities (Moubray [2], Bin Jabar [3]). Since the 1920s, non-destructive testing (NDT) has developed from a laboratory curiosity to an indispensable tool of production. No longer is visual examination the principal means of determining quality. Various non-destructive tests are in worldwide use to detect variations in structure, minute changes in surface finish, and the presence of cracks or other physical discontinuities; to measure the thickness of materials and coatings; and to determine other characteristics of industrial products (MCMaster and Wenk [4]).

This paper presents a new model that combines risk management, maintenance management, and inspection methodologies into a single model that could be used by maintenance managers and engineers to select an applicable maintenance strategy and inspection methodology based on the operational and business risks posed by the specific piece of equipment.

\subsection{Research objectives}

A case study approach was followed, based on the application of the newly developed model for actual static equipment. This study attempted to ascertain the applicability of generalised maintenance strategies on static equipment. The aim was to inter-link these maintenance strategies with applicable and usable inspection methodologies, combined with a risk-based approach to maintaining the equipment. The risk-maintenance-inspection model was developed in such a way as to ensure that it could be applied both to newly fabricated equipment and to equipment with a distinct operating history.

\section{LITERATURE}

A number of literature sources on maintenance strategies and approaches, inspection methodologies, and risk management are discussed briefly.

\subsection{Maintenance strategies}

\section{Breakdown maintenance}

The main feature of corrective maintenance (also referred to as run-to-failure) is that actions are only performed when a machine (equipment) breaks down. There are no interventions until a failure has occurred. During the period before the Second World War, breakdown maintenance was the dominant mode of managing maintenance. The approach was very reactive, and could probably be justified by the uncomplicated and overdesign of the physical assets in the time period (Kelly [5]).

\section{Preventive maintenance}

In most textbooks the term 'preventive maintenance' includes time-based maintenance and condition-based maintenance. In some instances, preventive maintenance is seen as being only time-based, while in others, the choice of maintenance on a component is seen as a combination of reliability characteristics, time, and condition of the component. Preventive maintenance is an equipment maintenance strategy based on replacing, overhauling, or re- 
manufacturing an item at a fixed interval, regardless of its condition at the time (Kwaliteg Management Services [6]).

\section{Predictive maintenance}

Predictive maintenance is a condition-based approach to maintenance (Bin Jabar [3]). It is based on the measurement of an asset's condition in order to assess whether the equipment will fail at some future time, and then taking action to avoid the consequences of the failure. This approach is more economical since labour, materials, and production schedules are used more efficiently (Bin Jabar [3]).

\section{Proactive maintenance}

Campbell [7] defined proactive maintenance as "a style of initiative that is anticipatory and planned for". Proactive maintenance concentrates on monitoring and correcting root causes of asset failures (Bin Jabar [3]).

\section{Opportunistic maintenance}

The possibility of using opportunistic maintenance is determined by the concurrence of control or substitution times for different components on the same machine or plant. This type of maintenance can lead to the whole plant being shut down at set times to perform all relevant maintenance interventions at the same time.

\subsection{Maintenance approaches}

\section{Reliability-centred maintenance (RCM)}

The two important goals for RCM are, first, to identify the maintenance requirements of a physical asset that meets the production goals; and second, to optimise the performance with real results (Campbell [7]).

\section{Business-centred maintenance}

This approach is aimed at achieving business objectives, which are then translated into maintenance objectives and used as the basis for formulating a maintenance strategy (Kelly [8]).

\section{Total productive maintenance}

This approach to maintenance management emphasises the importance of operator involvement in increasing equipment reliability (Campbell [7]).

\section{Risk-based maintenance (RBM)}

According to Jones [9], RBM uses exactly the same functional description of systems, subsystems, functional failures, and failure modes as RCM, but it is different in that the criticality class is replaced with an explicit risk calculation.

\section{Total quality maintenance}

TQMaint is a maintenance management approach that is based on the Deming cycle of plando-check-act (referred to as 'Deming P-D-C-A'). Another main feature of this approach is that maintenance is integrated with production and scheduled accordingly, allowing maintenance tasks to be scheduled and performed to avoid high production demand periods (Sherwin [10]). 


\subsection{Inspection methodologies}

As is well known, inspection procedures are not simply measurement techniques (i.e. a combination of physical principles, measuring methods, and equipment). They consist of a more complex process involving many elements such as equipment settings, calibration and functional examinations, examination work details, recording and illustration tools, software, and personnel (e.g. interpretation of indications relying on the skill of the operator). Of the various conventional and advanced non-destructive examination (NDE) methods, six are widely used for the examination of pressure vessels and tanks by certified pressure vessel inspectors. The names and acronyms of these six methods are provided by Alberta Boilers Safety Association [11]:

- $\quad$ Ultrasonic Techniques (UT)

- $\quad$ Gamma \& X-ray Radiography Techniques (RT)

- $\quad$ Eddy Currents Techniques (ET)

- $\quad$ Magnetic Particle Techniques (MT)

- $\quad$ Liquid Penetration Techniques (PT)

- Visual Examination Techniques (VT)

\subsection{Risk management}

For the purpose of this study, it was decided to use the tried and tested risk matrix adopted by the National Petroleum Refiners of South Africa (Natref). It is based on a $7 \times 7$ matrix i.e., a 7-point scale is used for both parameters. Risk is a function of the probability of a risk event occurring, and the direct or indirect consequences of the risk event. This tool (matrix and methodology) helps the decision-maker to establish the risks involved for a particular piece of equipment, and to manage these risks. After the risks are evaluated, a decision can be made whether the risk can be accepted, mitigated, or totally eliminated.

\section{NEW THEORETICAL MODEL}

\subsection{Model development}

Establishing the risk profile for a piece of equipment is the starting point of the model. Once the risk is established, the inspection methodologies and maintenance strategies are determined. The complete model, comprising four quadrants, is illustrated in Figure 1 . The right hand section is referred to as Quadrant 1, the bottom section as Quadrant 2, the left hand section as Quadrant 3, and the top section as Quadrant 4. The four quadrants of the model are discussed briefly below, but a more detailed discussion is provided by Jordaan [12].

\section{Quadrant 1: Consequence and effect establishment}

This quadrant focuses on the effect or impact that a particular failure (or failure mode) could have. It is based on the $7 \times 7$ risk matrix. It is limited to include significant scenarios of effects or consequences that will affect not only the bottom line of the company, but also its public image. It considers the impact severity, financial impact, safety and health impact, environmental impact, and legal impact. Table 1 below summarises the measurement criteria with the minimum and maximum consequence severity. In establishing the consequence scenario, several factors are to be included. It is recommended that a panel consisting of competent representation from all disciplines involved (i.e. maintenance, production, process, and inspection) be present to establish the consequence severity of a specific failure mode. In order to make it a quantifiable risk scenario, quantifiable information and decisions should be used.

\section{Quadrant 2: Probability and frequency establishment}

This quadrant focuses on the frequency or probability of the occurrence of a particular 
failure or failure mode. It is limited to include a typical range of easily interpretable frequencies or probabilities. It considers the frequency linked to the operating life cycle of the plant and the probability as a measure in occurrences per year. Table 2 below summarises the measurement criteria with the minimum and maximum frequencies and probabilities.

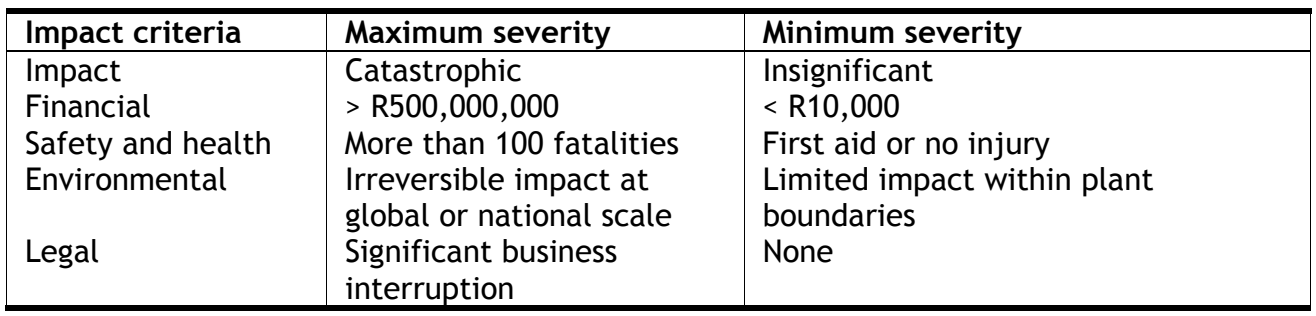

Table 1: Criteria for consequence severity

\begin{tabular}{|l|l|l|}
\hline Probability criteria & Maximum severity & Minimum severity \\
\hline $\begin{array}{l}\text { Frequency } \\
\text { Probability }\end{array}$ & $\begin{array}{l}\text { More than once per year } \\
10 \text { times per year }\end{array}$ & $\begin{array}{l}\text { Highly unlikely } \\
\text { Once in 100,000 years }\end{array}$ \\
\hline
\end{tabular}

Table 2: Criteria for probability

\section{Quadrant 3: Inspection methodology}

The basis of the development of this section of the model was: the higher the risk, the more intense the inspection should be. 'Intense' is referred to as a more intense physical inspection $(10 \%, 25 \%$, or $100 \%)$ and more sensitive detection methods.

\section{Quadrant 4: Maintenance strategies}

The model development for this quadrant was based on the principle that the lower the risk, the more lenient the strategy could be - and hence a breakdown or opportunistic strategy is followed. The higher the risk, the more detailed and documented and the less lenient the strategy should be. For the higher risk scenarios, a pro-active (preventive and predictive) strategy is to be followed. Coupled with this, the RBM approach is to be followed to determine and predict the failure mechanisms, and to enable the mitigation measures to prevent a failure.

\subsection{Use of the model}

The application and use of the model is described in a number of steps outlined below.

\section{Step 1: Identify failure modes}

Identify the specific failure modes or failure mechanisms. This is where the actual process conditions to which the equipment is subject are evaluated, to establish the possible causes of deterioration that could occur and the effect it will have on the integrity of the equipment. The aim is to consider all possible causes of deterioration. For example, having a carbon steel vessel in a chemical service, it would be expected that deterioration modes such as corrosion, erosion, cracking, flaking, etc. that might occur are evaluated. For pressure vessels in a petro-chemical facility, a database of deterioration such as the NACE database [13] could be used. The NACE database is a 'live database', updated by a committee of metallurgists worldwide, that lists all possible deterioration mechanisms, if certain products are put in contact with specific types of construction materials. It is based on a cumulative experience base of over 1,000 years. It is important not to neglect the run length of the piece of equipment under consideration when reviewing each of the failure 
mechanisms and modes. For example, a heat exchanger experiencing a corrosion rate of $1 \mathrm{~mm} /$ year is insignificant, if a piece of equipment can be repaired annually. However, the same corrosion rate on a vessel with $1 \mathrm{~mm}$ corrosion allowance that can only be inspected and maintained every three years is a major threat.

\section{Step 2: Evaluate the consequence of the failure}

Use Quadrant 1 in conjunction with the applicable information gathered in Step 1, as well as the competent representation from all disciplines involved (e.g. maintenance, production, process, and inspection) in order to establish the most likely consequence or effect, if a certain failure mode or failure mechanism is to occur. When considering the consequence or the effect of the failure, the key aspects to consider are the effect in terms of impact severity, financial implications, safety and health impact, impact on the environment, and the possible legal impact. It is recommended that the consequence determination be done in a sequential manner. First, establish the Impact severity of the failure, and plot it on the relevant effect in Quadrant 1. Then consider the financial implications relevant to the failure. Plot that on the relevant effect in Quadrant 1. Then consider the safety and health impact along with the other impact categories. After all the key aspects of the consequence and effects have been established, the one with the highest numerical score (1-7) is considered the worst possible consequence or effect of a particular failure mode or failure mechanism, as identified in Step 1. Although the other key consequences are then considered less relevant in determining the risk of that failure mode, they should be noted as they are used later in Steps 5 and 6 .

\section{Step 3: Evaluate the probability of failure}

Use Quadrant 2 in conjunction with the applicable information gathered in Step 1, and use the competent representation from all disciplines involved to establish the most likely frequency or probability of occurrence of the actual failure mode. Similar to Step 2, a sequential approach is to be followed. After this, the one with the highest numerical score (1-7) is considered the most frequent or most likely occurrence of a particular failure mode, as identified in Step 1.

\section{Step 4: Determine the risk associated with the failure}

On the $7 \times 7$ risk matrix, move horizontally from the consequence or effect selected in Step 2 , and vertically from the frequency or likelihood of occurrence selected in Step 3. Read the Risk Assessment Matrix (RAM) score on the 7x7 matrix where the two quadrants intersect. This RAM score will range from 2 to 14 . The interpretation of the RAM score must be seen in conjunction with the information gathered in Step 1. The lower the RAM score, the lower the risk that the actual failure mode or failure mechanism will be experienced as identified in Step 1, with the specific impingement on the integrity of the equipment under consideration. The higher the RAM score, the higher this particular risk. The light grey section in Figure 1 is deemed to be acceptable risk, with no action required except for basic risk management to prevent the risk from propagating into a higher score. The white section is considered to be medium risk, and risk mitigation measures are to be put in place to manage the risk. The dark grey section is seen as unacceptable risk, and immediate action is required to mitigate and manage the risk. 


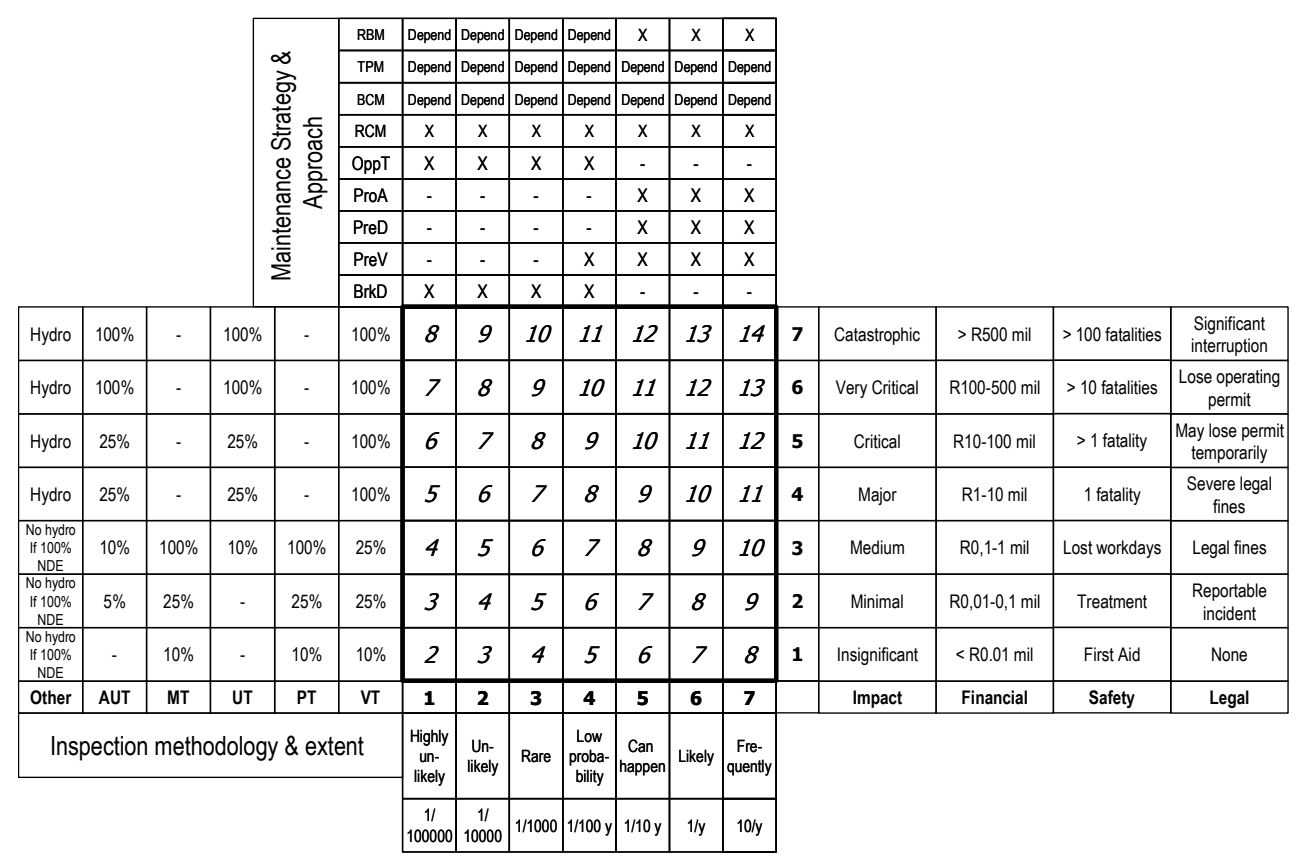

Figure 1: Framework for complete risk-based maintenance model

\section{Step 5: Identify inspection methodologies}

From the identified RAM score intersection in Step 4, move horizontally across to Quadrant 3. Read off the applicable inspection methodologies and extent (10-100\%). If a percentage value is stipulated in the horizontal plane from the RAM score, then the inspection methodology specified in Quadrant 3 shall be applied to the specific piece of equipment in the context of the specific failure mode as identified in Step 1. Refer to Table 3 for an interpretation of the percentage. Test the specified inspection methodologies with competent representation from all the disciplines involved for applicability and practicality for that specific equipment.

\begin{tabular}{|l|l|}
\hline$\%$ as specified & Interpretation \\
\hline $10 \%$ & Minimum of $10 \%$ of accessible areas, at the discretion of the owner \\
$25 \%$ & Minimum of $25 \%$ of accessible areas, at the discretion of the owner \\
$100 \%$ & All accessible areas \\
\hline
\end{tabular}

Table 3: Interpretation of percentage specified in Quadrant 3

Step 6: Identify maintenance strategy and approach

From the identified RAM score intersection in Step 4, move vertically to Quadrant 4. Read off the most suitable maintenance strategy. If an $X$ is stipulated in the horizontal plane from the RAM score, then the maintenance strategy and approach specified in Quadrant 4 shall be applied to the specific piece of equipment in the context of the specific failure mode or mechanism identified in Step 1. If a 'Depends' is encountered, the detailed information gathered in Step 1 is to be reviewed in the context of the specified maintenance strategy and approach. Test the specified strategy and approach with competent representation from all the disciplines involved for applicability and practicality for that specific equipment. 


\section{CASE STUDY FINDINGS}

The methodology for the applicability of the model is based on case study evaluation and applicability testing. After the case studies were evaluated, the model in Figure 1, together with the six steps discussed above, was followed to establish the most suitable inspection methodology and maintenance strategy/ approach for each case. After the model was applied, the maintenance strategy and approach was specified (from the model) with a combination of inspection methodologies and intensity. Using actual findings from inspection reports, and actual maintenance done on the equipment, the applicability of the specified strategy, approach, and inspection methodologies and intensity was tested.

\subsection{Case Study 1: Crude column}

Step 1: Failure modes and failure mechanisms

The possible means of deterioration in equipment integrity established from a competent metallurgist, based on operating medium and material of construction, is pitting corrosion and flaking corrosion.

\section{Step 2: Consequence of failure}

From Table 4 below, the highest score for consequence is 6 (safety and health impact).

\begin{tabular}{|l|c|l|}
\hline Impact & Score & Description \\
\hline Severity impact & 5 & Critical \\
Financial impact & 5 & R10m - R100m \\
Safety and health impact & 6 & More than 10 fatalities \\
Environmental impact & 5 & Very serious long term reversible impact - \\
& 3 & Regional level \\
Legal impact & Legal fines \\
\hline
\end{tabular}

Table 4: Impact values from Quadrant 1

\section{Step 3: Probability or likelihood of failure}

Score $=5$ - Once in ten years (can happen)

Step 4: RAM score

Values of 6 and 5 intersect at a RAM score $=11$

\section{Step 5: Inspection methodologies}

With a consequence value of 6 , the applicable inspection methodologies are:

- $100 \%$ visual inspection

- $100 \%$ ultrasonic testing

- $100 \%$ automated ultrasonic testing

- $\quad$ Full hydro testing

\section{Step 6: Maintenance strategy and approach}

With a probability value of 5 , the suitable maintenance strategy and approaches are:

- $\quad$ Specified strategy: RCM or RBM

- $\quad$ Specified approach: Pro-active maintenance, predictive maintenance and preventive maintenance 


\section{Discussion on inspection methodologies}

From the operational history and the inspection reports, it is seen that the most common failure mechanism is pitting corrosion, with a few isolated cases of flaking corrosion and stress-related cracks. From the model, the specified inspection methodologies are visual testing (inspection) and ultrasonic testing or automated ultrasonic testing. VT is effective in determining surface defects, such as pitting corrosion and flaking corrosion. UT is also effective in the detection of pitting corrosion, with a limitation on the areas that can be done. AUT is very effective in the detection of pitting and flaking corrosion. If the specified inspection methodologies had been applied to the equipment, the risk of pitting or flaking failures would have been substantially reduced. The benefit of AUT would be that it would also be able to detect the stress-related cracks prior to failure.

\section{Discussion on maintenance strategy and approach}

The maintenance strategy specified by the model is RCM or RBM, and the approach to be followed is that of proactive, preventive and predictive maintenance. Based on the maintainability of the equipment (once every three years), it is deemed that the RBM strategy with a proactive approach would best suit the application. Verifying this with the current maintenance strategy and approach, it can be seen that the model specifies a more conservative strategy and approach than is currently applied. Therefore, optimisation of the current strategy could be implemented to ensure that the optimum level of maintenance is performed on the equipment.

\subsection{Case Study 2: Crude desulphuriser reactor}

\section{Step 1: Failure modes and failure mechanisms}

A competent metallurgist established that there were no possible means of deterioration in equipment integrity, based on operating medium and material of construction. From a mechanical design and maintenance perspective, the failure mode of cracking in the welding and gasket faces was identified, as this is high pressure equipment that is subjected to systematic cyclic loading in terms of pressure and temperature. In addition, minor mechanical damage was seen as a possible cause of stress raisers, due to the catalyst forming hard 'rocks'. These rocks are mechanically broken up into small pieces for removal during catalyst change activities that take place biannually. Note that this is a high pressure and high temperature reactor.

\section{Step 2: Consequence or effect of failure}

From Table 5 below, the highest score for consequence is 7 (severity as well as legal impact).

\section{Step 3: Probability or likelihood of failure}

Score $=4$ - Once in operation lifetime

\section{Step 4: RAM score}

Values of 7 and 4 intersect at a RAM score $=11$

Step 5: Inspection methodologies

- $100 \%$ visual inspection

- $100 \%$ ultrasonic testing

- $100 \%$ automated ultrasonic testing

- $\quad$ Full hydro testing 


\begin{tabular}{|l|c|l|}
\hline Impact & Score & Description \\
\hline Severity impact & 7 & Catastrophic \\
Financial impact & 6 & R100m - R500m \\
$\begin{array}{l}\text { Safety and health } \\
\text { impact }\end{array}$ & 6 & More than 10 fatal \\
Environmental impact & 5 & $\begin{array}{l}\text { Very serious long term reversible impact - Regional } \\
\text { level }\end{array}$ \\
Legal impact & 7 & Significant business interruption \\
\hline
\end{tabular}

Table 5: Impact values from Quadrant 1

\section{Step 6: Maintenance strategy and approach}

- $\quad$ Specified strategy: RCM

- $\quad$ Specified approach: Opportunistic maintenance, preventive maintenance, or breakdown maintenance

\section{Discussion on inspection methodologies}

From the operational history and the inspection reports, it is seen that the most common failure mechanism is cracking and mechanical damage. From the model, the specified inspection methodologies are visual testing (inspection) and ultrasonic testing or automated ultrasonic testing. VT is effective in determining surface defects such as surface cracking and surface defects such as mechanical damage. UT is effective in detecting sub-surface discontinuities and cracks, with a limitation on the areas that can be done. AUT is highly effective in detecting cracks and discontinuities. If the specified inspection methodologies had been applied to the equipment, the risk of cracking or mechanical damage failures would have been substantially reduced. The benefit of the AUT is the ability to detect the stress-related cracks prior to failure. A possible shortfall here would be the detection of surface cracks on the flange faces, due to excessive forces exerted by bolting. However, this was highlighted by the expert panel as a possible failure mode, and therefore it is recommended that the $100 \%$ VT be focused on the flange faces, and that any suspect area be PT tested.

\section{Discussion on maintenance strategy and approach}

The maintenance strategy specified by the model is RCM, and the approach to be followed is that of preventive, opportunistic or breakdown maintenance. Based on the maintainability of the equipment (minor inspection and maintenance every six months, and full inspection and maintenance once every three years), it is deemed that the RCM strategy with a preventive approach would best suit the application. Verifying this with the current maintenance strategy and approach, it can be seen that the model specifies a similar strategy and approach to that which is currently applied. However, the concern is whether the specification of breakdown maintenance is an acceptable approach for such a high consequence of failure type of equipment. Emphasis is placed on the concept of risk, which is based not only on consequence, but also on the probability or likelihood of the occurrence of such a risk event. In this particular case the probability of occurrence is in the order of 0,01 or $1 \%$, and this brings the overall risk down. In retrospect, this could be seen as a $99 \%$ probability of never occurring, which makes it easier to comprehend. It is important that the concept of risk be fully grasped by all members of the expert panel in order to appreciate why a catastrophic failure risk event could be regarded as acceptable if it has a $1 \%$ probability of occurring (or a $99 \%$ probability of never happening).

\section{CONCLUSION}

Based on the results obtained from the case studies, we conclude that the newly-developed model can be applied to static equipment to establish an applicable maintenance strategy and approach, as well as applicable inspection methodologies. It serves the purpose of 
being an optimised, consolidated, and usable model of inspection methodologies, maintenance strategies, and/or risk management principles that is generically applicable to static equipment. It was shown that it could be used to enable maintenance managers and engineers to select an applicable maintenance strategy and inspection methodology, based on the operational and business risks posed by the specific piece of equipment.

The model application methodology has six steps, which logically focus on the different aspects of the model application - namely, risk (consequence and probability), inspection methodology and maintenance (strategy and approach). The deciding factor and starting point of the model is the determination of the RAM score using Quadrants 1 and 2 of the model (refer to Figure 1). The process involved in this determination is quite intense and time-consuming. After the RAM score has been selected, the outcome of the model is the specification of inspection methodologies, applicable maintenance strategies, and maintenance approaches, which are obtained from Quadrants 3 and 4 of the model.

In all the case studies it was shown that the specified inspection methodologies would have detected the actual failure mechanisms and failure modes that occurred during the operation of the equipment. Similarly, the specified maintenance strategy and approach was deemed suitable for the application. The applicability of the model is far reaching, and it is possible to use it for different disciplines. In the group of companies, the $7 \times 7$ risk matrix is the only accepted standard for risk establishment. Therefore the establishment of the RAM score is consistent across all disciplines. If the RAM score for a piece of equipment is set by an expert panel, then the only variable that the model could offer is the customisation of Quadrants 3 and 4 in the model (refer to Figure 1). For instance, these two quadrants could be developed for civil maintenance. Similar to the model in Figure 1, Quadrant 3 could be used to specify inspection methodologies, but customised with the relevant and applicable inspection methodologies used in civil maintenance today. Similarly, Quadrant 4 could be customised to include maintenance strategies or approaches for civil maintenance. Another example is that the production department can customise these quadrants to specify the necessary control and protection means, based on the RAM score of a piece of equipment.

The limitation of the model is that a thorough understanding of the concept and application of risk management is needed, as it is quite evident that risk forms the basis of the model. From a practical perspective (during the case study expert review), it was clear that all of the experts selected to form the review panel were not completely familiar with the concept of risk, and this presented quite a challenge. To overcome this obstacle, it is recommended that a risk expert be contracted as a facilitator of the review session. Another limitation in the use of the model is the intense drain on resources. In order to get an accurate RAM score, these resources are required, and it might be difficult to allocate these resources to an assignment at the same time for an extended period of time. It is recommended that the session be split up into smaller, more manageable chunks, and that certain aspects are handled per sub-session. After these sub-sessions have been completed, only a core team need be assembled to apply the model and establish the specified maintenance strategy, approach, and inspection methodologies.

\section{NOMENCLATURE}

BCM Business-centred maintenance

ET Eddy Currents Technique

MT Magnetic Particle Technique

PT Liquid Penetrate Technique

RBM Risk-based maintenance

RCM Reliability-centred maintenance

RT Gamma and X-ray Radiography Technique

TPM Total productive maintenance

UT Ultrasonic Technique

VT Visual Examination Technique 


\section{REFERENCES}

[1] Visser, J.K. 1996. A conceptual framework for the understanding and teaching of maintenance management. ICOMS, Melbourne, May 1996.

[2] Moubray, J.M. 2000. Maintenance management - A new paradigm. www.MaintenanceResources.com.

[3] Bin Jabar, H. 2003. Plant maintenance strategy: Key for enhancing profitability. www.MaintenanceResources.com.

[4] McMaster, R.C. and Wenk, S.A. 1951. A basic guide for management's choice of non-destructive tests. Special Technical Publication No. 112. Philadelphia, PA: American Society for Testing and Materials.

[5] Kelly, A. 1989. Maintenance and its management. Southampton: Conference Communication.

[6] Kwaliteg Management Services, www.kwaliteg.co.za

[7] Campbell, J.D. 1995. Uptime: Strategies for excellence in maintenance management. Productivity Press, New York.

[8] Kelly, A. 1997. Maintenance: Organization and systems. Butterworth-Heinemann, Oxford.

[9] Jones, R.B. 1995. Risk-based management: A reliability-centered approach. Gulf Publishing Company.

[10] Sherwin, D. 2000. A review of overall models for maintenance management. Journal of Quality in Maintenance Engineering, 6 (No 3).

[11] Alberta Boilers Safety Association (ABSA). 2002. Inspection and servicing requirements for pressure equipment.

[12] Jordaan, J. 2005. A new maintenance strategy model for static equipment using inspection methodologies and risk management. Project Report for MSc (Applied Sciences) degree, University of Pretoria.

[13] National Association of Corrosion Engineers, NACE, www.nace.org. 